\title{
Design of grinding wheel profile for a new micro drill flute
}

\begin{tabular}{|r|l|}
\hline Journal: & Transactions of the Canadian Society for Mechanical Engineering \\
\hline Manuscript ID & TCSME-2017-0048.R2 \\
\hline Manuscript Type: & Article \\
\hline Complete List of Authors: & $\begin{array}{l}\text { Nguyen, Danh-Tuyen; National Tsing Hua Universtiy, Institute of } \\
\text { NanoEngineering and MicroSystems } \\
\text { Nguyen, Hai-Anh; National Chiao Tung University, Mechanical Engineering } \\
\text { Lee, An-Chen; National Chiao Tung University, Mechanical Engineering }\end{array}$ \\
\hline $\begin{array}{r}\text { Is the invited manuscript for } \\
\text { consideration in a Special } \\
\text { Issue? : }\end{array}$ & N/A \\
\hline Keywords: & $\begin{array}{l}\text { grinding wheel profile, grinding wheel, grinding design, new micro drill } \\
\text { flute, vericut }\end{array}$ \\
\hline \multicolumn{2}{|c}{}
\end{tabular}




\title{
Design of grinding wheel profile for a new micro drill flute
}

\author{
Danh-Tuyen Nguyen ${ }^{1}$, Hai-Anh Nguyen ${ }^{2}$, An-Chen Lee ${ }^{3}$ \\ ${ }^{1}$ Institute of NanoEngineering and NanoSystems, National TsingHua University, \\ No. 101, Section 2, Kuang-Fu Road, Hsinchu, Taiwan 30013, R.O.C. \\ ${ }^{2,3}$ Department of Mechanical Engineering, National Chiao Tung University, $1001 \mathrm{Ta}$ \\ Hsueh Road, Hsinchu 30010, Taiwan \\ E-mail: ${ }^{1}$ tuyen3586@gmail.com
}




\begin{abstract}
Derived from our previous researches, a new micro drill bit with higher accuracy and productivity was developed. Because the drill flute plays a significant role in its cutting performance, the design of grinding wheel profile for the new micro drill flute by an inverse problem method is concerned in this research. First of all, the crosssection of the new micro drill flute is modeled as mathematical equations. Second, machine parameters and work-piece geometric parameters are set up. Third, the engagement equation between the grinding wheel and flute surfaces is developed. Fourth, that equation is solved to get the locus of contact points. Finally, the translation and rotation transformations of that locus are carried out to obtain the grinding wheel profile for the new micro drill flute. Numerical examples are demonstrated and validated by Vericut software.
\end{abstract}

\title{
Keywords
}

Grinding wheel profile, grinding wheel, grinding design, new micro drill flute, vericut 


\section{Introduction}

Because of science and technology development, there is an extremely high demand for drilling micro holes in many products, such as fuel injection nozzles, cameras, mobile phones, medical instruments, micro dies and molds, computers, watches, bearings, especially printed circuit boards (PCB), at present. Hence, many researchers have been striving to improve the cutting ability of micro drills. Their researches often focused on the cutting force, tool wear, new material, and some geometric parameters, such as point angle, helix angle, flute length to drill diameter ratio (Chyan \& Ehmann, 1998; X. Huang, Chen, Wang, Zheng, \& Song, 2016; S. Zhang et al., 2016; Zhaojun, Wei, Yanhong, \& Lijiang, 1998). The geometry of the micro drill bit was not changed much until our research. Derived from our previous research, the new micro drill with the new locus of cutting edges was developed, i.e., the cutting lips are in the plane containing its axis, so the new micro drill has great distribution of cutting angles along its cutting edges. (A.-C. Lee \& Hoang, 2016; A.-C. Lee, Nguyen, \& Wu, 2014; A. C. Lee, Horng, Tuyen, \& Hsiao, 2013). The normal rake and clearance angles along its cutting lips are positive and constant, respectively. It makes new micro drill to have very good cutting performance, for example, reducing the cutting force, power requirement, as well as the avoidance of the formation of a built-up edge. Furthermore, the dynamic analysis of the micro drill makes it to have higher accuracy (A.-C. Lee \& Nguyen, 2016). Because the drill flute has a high impact to the drill character, such as 
cutting angles, strength, stability, chip removing and dynamic behavior (W. Zhang, Wang, He, \& Xiong, 2006), grinding of the drill flute is an important work of generating the new micro drill. Grinding is a machining process utilizing abrasives for the removal of material. These abrasives act as cutting tools to remove tiny chips from work-piece. They are popularly made of silicon carbide, aluminum oxide or fine diamond grains. The coarse-size abrasive is used to fast remove material of work-piece, and smaller one is used to do a finer finish. Wheel bond with three main kinds of vitrified bond, organic bond and metal bond holds the abrasives together to form grinding wheel. It affects to the strength and wear resistance of grinding wheel. When the protrusion of abrasives on the grinding wheel surface is small, the grinding wheel gets blunt. Dressing operation is performed to sharpen grinding wheel. When the grinding wheel that is out of shape due to wear and deformation, the trueing operation is performed to restore the shape of the grinding wheel. Dressing or truing operation is based on the grinding wheel profile. Hence, the developing process of the grinding wheel profile play an extremely crucial role in grinding wheel design. As a result, this research presented the developing process of the grinding wheel for the new micro drill flute.

The grinding process is a basic operation in manufacturing solid rotary cutting tool, and characterized by complex partial spatial contact between the blank and grinding wheel. Its main problem is the achievement of the desired flute profile (Karpuschewski, Jandecka, \& Mourek, 2011). Identical flutes can be manufactured under very different conditions with respect to machine setup and tool geometry used. Hence, the choices of the operating parameters and cutter profiles depend on the 
machine operator and his know-how (Ehmann \& DeVries, 1990). There are two main approaches of obtaining the desired profile of the drill flute. The direct problem method is to evaluate the cross-section of the drill flute from a given grinding wheel profile, position of the grinding wheel, drill pitch. The inverse problem approach is to determine the grinding wheel profile for its given position, desired cross-section of the drill flute, and drill pitch. The key difference of two methods is in their inputs and outputs (Chen \& Rowe, 1996; Karpuschewski et al., 2011; Sheth \& Malkin, 1990; Xie, Zheng, Zhou, \& Lin, 2011).

Because the new micro drill flute is given, which is developed from our previous work (A.-C. Lee et al., 2014), the inverse problem method was applied in this study. First of all, the cross-section of the new micro drill flute is modeled by mathematical equations. Second, the machine parameters and work-piece geometric parameters are set up. Third, the engagement equation between the grinding wheel and the flute surface is developed. Fourth, that equation is solved to get the locus of contact points. Finally, the translation and rotation transformations of that locus are carried out to obtain the grinding wheel profile for the new micro drill flute. Numerical examples were demonstrated and the accuracy was validated by Vericut software.

\section{Mathematical model of a new micro drill flute}


The new micro drill was developed as shown in Figure 1. It is a planar micro drill of which main cutting lips are in the plane containing its axis and the intersection between the micro drill flute and flank surfaces. Figure 2 shows five main steps to machine the new micro drill (C. Huang, Tarng, Chiu, \& Huang, 2009). Step 1: cutting a round rod in shorter ones with the suitable lengths. Step 2: grinding the rod to make it straight and to be in the diameter of the micro drill shank. Step 3: grinding the conical and cylindrical parts. Step 4: grinding the flute of the new micro drill. The helix angle is the angle between axial axes of the grinding wheel and the new micro drill. Step 5: grinding flank surfaces to generate cutting lips. The drill flute has a high impact to the drill character, such as cutting angles, strength, stability, heat dissipating, chip removing and dynamic behavior (W. Zhang et al., 2006). Especially, it combines with flank surfaces to generate cutting lips, which is crucial part of the drill bit. As a result, the new drill flute plays a significant role in the drill bit. Design of grinding wheel profile for grinding the drill flute in step 4 is an important work of generating the new micro drill.

The flute formed by sweeping helically the cross-section at the drill tip $\mathrm{O}$ is shown in Figure 3. Because curves $\mathrm{ABC}$ and $\mathrm{A}^{\prime} \mathrm{B}^{\prime} \mathrm{C}^{\prime}$ are symmetric, it is only necessary to evaluate curve ABC.

Portion $\mathrm{AB}$ as shown in Figure 3 creates the main cutting lip of the new micro drill. Derived from our research (A.-C. Lee et al., 2014), it is described by Eqs. 1 and 2. 


$$
\begin{aligned}
& x=f_{1}(u)=u \cdot \frac{\sin (u+\psi) L \tan (\rho)}{2 \pi \cos (\psi)} \\
& y=f_{2}(u)=u \cdot \frac{\cos (u+\psi) L \tan (\rho)}{2 \pi \cos (\psi)}
\end{aligned}
$$

where $\psi$ and $\rho$ as shown in Figure 4 are chisel angle calculated by Eq. 3, semi-point angle is calculated by Eq. 4, respectively. $L$ is helix pitch and evaluated by $L=2 \pi R \cot \left(\mathrm{h}_{0}\right)$, where $R$ and $\mathrm{h}_{0}$ are the radius of the new micro drill and helix angle, respectively.

$$
\begin{gathered}
\rho=\frac{\left(\tan \beta_{1}^{\prime}-\tan \beta_{2}^{\prime}\right) \cot \phi_{1}^{\prime}}{\tan \beta_{1}^{\prime}+\tan \beta_{2}^{\prime}} \\
\psi=-\tan ^{-1}\left(\frac{2 \cos \phi_{1}^{\prime}}{\tan \beta_{1}^{\prime}+\tan \beta_{2}^{\prime}}\right)
\end{gathered}
$$

where $\phi_{1}^{\prime}$ is primary semi-point angle, $\beta_{1}^{\prime}$, and $\beta_{2}^{\prime}$ are tilt angles as shown in Figure 4

Portion BC creating the secondary cutting lips of the new micro drill is an arc and is described by Eqs. (5) and (6).

$$
\begin{aligned}
& x=f_{1}(u)=X_{O_{1}}-R_{1} \cos u \\
& y=f_{2}(u)=Y_{O_{1}}+R_{1} \sin u
\end{aligned}
$$


where $-\alpha_{2} \leq u \leq \alpha_{1}, X_{O_{1}}$ and $Y_{O_{1}}$ are the $\mathrm{x}$ and $\mathrm{y}$ coordinates of $\mathrm{O}_{1}, R_{1}$ is the radius of arc $\mathrm{BC}, \alpha_{2}$ and $\alpha_{1}$ are given parameters.

\section{Determination of grinding wheel profile for the new micro drill flute}

The new micro drill flute is generated by a grinding process as shown in Figure 5 (Kang, Ehmann, \& Lin, 1996). The cylindrical work-piece or the new micro drill has translation and rotation motions and the grinding wheel has rotation motion during grinding process. Coordinate systems $X_{M} Y_{M} Z_{M}, X_{W} Y_{W} Z_{W}$, and $X_{T} Y_{T} Z_{T}$ are assigned to the frames of stationary machine (fixed), work-piece, and tool or grinding wheel, respectively. It is assumed that $Z_{W}$-axis is coincident with the $Z_{M}$-axis; $Z_{T}$-axis is coincident with the tool axis, origin $\mathrm{O}_{\mathrm{T}}$ is located at tool coordinates $\left(a_{x}, a_{y}, a_{z}\right)$, and $\lambda$ is the rotational angle of the tool frame about $X_{T}$-axis.

The grinding wheel profile for the flute is determined by the inverse problem approach. The fundamental condition of engagement in the inverse problem is that the common normal at the contact point between the grinding wheel and the flute surface must intersect the grinding wheel axis. Or in other words, the common normal $\boldsymbol{n}$ at the contact point $\mathbf{P}$ between the grinding wheel and the flute surfaces intersects the axis of grinding wheel at point $\mathbf{Q}$ as shown in Figure 6. The engagement condition is described in coordinate system $X_{M} Y_{M} Z_{M}$ by: 


$$
\left(\boldsymbol{r}_{\mathrm{W}}-\boldsymbol{r}_{\mathrm{D}}\right) \cdot\left(\boldsymbol{Z}_{\mathrm{T}} \times \boldsymbol{n}\right)=0
$$

where vectors $\boldsymbol{r}_{\mathrm{W}}, \boldsymbol{r}_{\mathrm{D}}, \boldsymbol{Z}_{\mathrm{T}}$, and $\boldsymbol{n}$ are shown in Figure 6, and evaluated as follows:

$\boldsymbol{Z}_{\mathrm{T}}$ is the unit vector defining the tool axis, and evaluated by:

$$
\boldsymbol{Z}_{\mathrm{T}}=[0,-\sin \lambda, \cos \lambda]^{t}
$$

$\boldsymbol{r}_{\mathrm{D}}$ presents the coordinates of the tool frame origin is calculated by:

$$
\boldsymbol{r}_{\mathrm{D}}=\left[a_{x}, a_{y}, a_{z}\right]^{t}
$$

The radical cross-section of the flute surface in the $X_{\mathrm{W}} Y_{\mathrm{W}}$-plane is described in coordinate system $X_{W} Y_{W} Z_{W}$ by:

$$
{ }^{\mathrm{W}} \boldsymbol{r}_{\mathrm{W}}=\left[f_{1}(u), f_{2}(u), 0\right]^{t}
$$

where $t$ denotes the transpose of a matrix, $u$ is curvilinear parameter. The flute surface is created by rotating the radical cross-section around the $Z_{\mathrm{W}}$-axis through an angle $v$ as well as simultaneously translating it along the $Z_{\mathrm{w}}$-axis through a distance $(k \cdot v)$. Therefore, with the application of Eq. 10, the position vector of an arbitrary contact point is evaluated in the coordinate system $X_{M} Y_{M} Z_{M}$ by:

$$
\boldsymbol{r}_{\mathrm{W}}=\left[\begin{array}{c}
{ }^{\mathrm{M}} x_{\mathrm{W}} \\
{ }^{\mathrm{M}} y_{\mathrm{W}} \\
{ }^{\mathrm{M}} z_{\mathrm{W}}
\end{array}\right]=\left[\begin{array}{c}
f_{1}(u) \cos v-f_{2}(u) \sin v \\
f_{1}(u) \sin v+f_{2}(u) \cos v \\
k \cdot v
\end{array}\right]
$$


The $\boldsymbol{n}$ in Eq. 7 is the common normal vector at an arbitrary contact point on the flute surface and evaluated by

$$
\boldsymbol{n}=\left(\boldsymbol{r}_{\mathrm{w}}\right)_{u} \times\left(\boldsymbol{r}_{\mathrm{w}}\right)_{v}
$$

where $\left(\boldsymbol{r}_{\mathrm{w}}\right)_{u}=\frac{\partial \boldsymbol{r}_{\mathrm{w}}}{\partial u},\left(\boldsymbol{r}_{\mathrm{w}}\right)_{v}=\frac{\partial \boldsymbol{r}_{\mathrm{w}}}{\partial v}$. Substituting Eq.11 into Eq.12, we obtain:

$$
\boldsymbol{n}=\left[\begin{array}{c}
k\left[\dot{f}_{1}(\mathrm{u}) \sin v+\dot{f}_{2}(u) \cos v\right] \\
-k\left[\dot{f}_{1}(u) \cos v-\dot{f}_{2}(u) \sin v\right] \\
f_{1}(u) \dot{f}_{1}(u)+f_{2}(u) \dot{f}_{2}(u)
\end{array}\right]
$$

From Eqs. 7, 8, 9, 11, and 13, we obtain the engagement condition equation as:

$$
[A(u) \sin v+B(u) \cos v+C(u)]+[D(u) \sin v+E(u) \cos v] v=0
$$

where

$$
\begin{aligned}
& A(u)=\left[F(u) f_{2}(u)-k a_{z} \dot{f}_{1}(u)\right] \sin \lambda-k\left[a_{y} \dot{f}_{1}(u)-a_{x} \dot{f}_{2}(u)\right] \cos \lambda \\
& F(u)=f_{1}(u) \dot{f}_{1}(u)+f_{2}(u) \dot{f}_{2}(u) \\
& B(u)=-\left[F(u) f_{1}(u)+k a_{z} \dot{f}_{2}(u)\right] \sin \lambda-k\left[a_{x} \dot{f}_{1}(u)+a_{y} \dot{f}_{2}(u)\right] \cos \lambda \\
& C(u)=F(u)\left(a_{x} \sin \lambda+k \cos \lambda\right) \\
& D(u)=k^{2} \dot{f}_{1}(u) \sin \lambda \\
& E(u)=k^{2} \dot{f}_{2}(u) \sin \lambda
\end{aligned}
$$


where only $v$ is unknown, while the other parameters, such as $a_{x}, a_{y}, a_{z} \lambda, u$, and $k$ as shown in Figure 5 are set up, where $k=\frac{L}{2 \pi}$. Therefore, after solving Eq. 14, $v$ is obtained, and substituting it into Eq. 11, we obtain the locus of the contact points in the stationary machine frame $X_{M} Y_{M} Z_{M}$. In order to obtain the grinding wheel profile, the line of contact should be expressed in the tool frame $X_{T} Y_{T} Z_{T}$ by utilizing the relationship between these frames.

The axial cross-section of the tool in the $X_{T} Z_{T}$-plane with respect to the tool frame $X_{T} Y_{T} Z_{T}$ can be presented by:

$$
{ }^{\mathrm{T}} \boldsymbol{r}_{\mathrm{t}}\left(u_{t}\right)=\left[g_{1}\left(u_{t}\right), 0, g_{2}\left(u_{t}\right)\right]^{t}
$$

The surface of the tool can be obtained by revolving the cross-section about the $Z_{T}$ axis and expressed as follows

$$
{ }^{\mathrm{T}} \boldsymbol{r}_{\mathrm{t}}\left(u_{t}, v_{t}\right)=\left[\begin{array}{c}
{ }^{T} x_{T} \\
{ }^{T} y_{T} \\
{ }^{T} z_{T}
\end{array}\right]=\left[\begin{array}{l}
g_{1}\left(u_{t}\right) \cos v_{t} \\
g_{1}\left(u_{t}\right) \sin v_{t} \\
g_{2}\left(u_{t}\right)
\end{array}\right]
$$

where $u_{t}$, and $v_{t}$ represent the curvilinear coordinates of the surface.

The tool frame $X_{T} Y_{T} Z_{T}$ is defined by $\operatorname{Rot}\left(X_{T}, \lambda\right)$ and $\operatorname{Trans}\left(a_{x}, a_{y}, a_{z}\right)$ in the machine frame $X_{M} Y_{M} Z_{M}$. As a result, there is another way to express the contact curve for the grinding wheel in the tool frame as follows 


$$
\begin{aligned}
& { }^{\mathrm{T}} \boldsymbol{r}_{\mathrm{t}}\left(u_{t}, v_{t}\right)=\left[\begin{array}{cccc}
1 & 0 & 0 & 0 \\
0 & \cos \lambda & \sin \lambda & 0 \\
0 & -\sin \lambda & \cos \lambda & 0 \\
0 & 0 & 0 & 1
\end{array}\right]\left[\begin{array}{cccc}
1 & 0 & 0 & -\mathrm{a}_{x} \\
0 & 1 & 0 & -\mathrm{a}_{y} \\
0 & 0 & 1 & -\mathrm{a}_{z} \\
0 & 0 & 0 & 1
\end{array}\right] \boldsymbol{r}_{\mathrm{W}}
\end{aligned}
$$

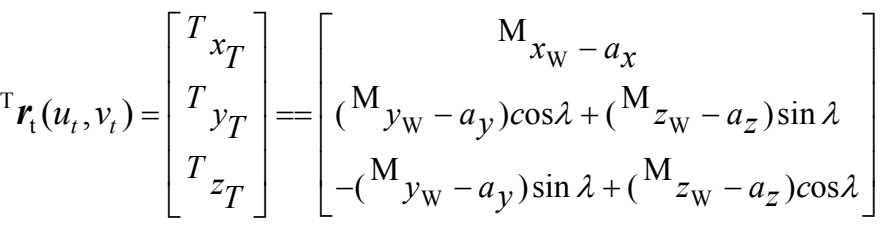

where $\mathrm{M}_{x_{\mathrm{W}}},{ }^{\mathrm{M}} y_{\mathrm{W}}$, and $\mathrm{M}_{z_{\mathrm{W}}}$ are evaluated by Eq. (11).

From Eqs. 15 and 16, we obtain:

$$
\left[\begin{array}{l}
g_{1}\left(u_{t}\right) \\
0 \\
g_{2}\left(u_{t}\right)
\end{array}\right]=\left[\begin{array}{l}
-\sqrt{\left({ }^{T} x_{T}\right)^{2}+\left({ }^{T} y_{T}\right)^{2}} \\
0 \\
{ }^{T} z_{T}
\end{array}\right]
$$

Because $\left({ }^{T} x_{T},{ }^{T} y_{T},{ }^{T} z_{T}\right)$ are calculated by Eq. $17,\left(g_{1}\left(u_{t}\right), g_{2}\left(u_{t}\right)\right)$ are then consequently obtained. Therefore, the grinding wheel surface is developed.

From the above analyses, the specific solution steps of determining the grinding wheel profile are the following (Kang, Ehmann, \& Lin, 1997):

1. Define the various machining parameters $\left(a_{x}, a_{y}, a_{z}, \lambda\right.$, micro drill radius $R$, and helix pitch $L$, or helix angle $h_{0}$ ).

2. Determine the variation range of $\mathrm{u}$ in Eq. 10, i.e. $u_{\min } \leq \mathrm{u} \leq u_{\max }$. 
3. Define the cross-section of the new micro drill flute, Eq. 10. It is developed by rotating the cross-section described by Eqs. 1, 2, 5 and 6 an angle $\gamma$ around the Z-axis. The starting value of $\mathrm{u}$ is $u_{\min }$.

4. Evaluate the nonlinear engagement condition, Eq. 14, with respect to parameter $v$.

5. Determine the resulting locus of contact points (in tool coordinates) by utilizing Eq. 17.

6. Determine the cross section of the required tool in the $X_{T} Z_{T}$ - plane by using Eq. 18 .

7. Steps 3 through 6 are repeated for discrete values of $u$ in the range given in step 2 .

Based on above steps, the grinding wheel profile for the new micro single flute drill is developed.

\section{Results}

Two numerical demonstrations are given in this section. The parameters are set up as shown in table 1. The profile $\mathrm{ABC}$ in Figure 3 is named as the desired cross-section of the new micro drill flute. Figures 7 and 9 shows two desired cross-sections of the new micro drill flute corresponding cases I and II in table 1.

Applying the parameters with cases I and II in table 1 as well as sections 2 and 3, it yields two grinding wheel profiles corresponding to cases I and II for the new micro drill flute as shown in Figure 8 and 10. Based on these grinding profiles, the solid model 
of the grinding wheel is developed. Figure 11 illustrates the solid model of the grinding wheel corresponding to case I.

To verify the design procedure and check the accuracy of grinding wheel profile, we employed Vericut software for numerical simulation and animation of the grinding process of the new drill flute. The input data include solid models of a cutting tool, work-piece and their toolpaths and the output data is the desired flute. The grinding wheel profile for case I is shown in Figure 11. The simulation includes four main works. First of all, a 9-axis CNC grinding machine as shown in Figure 12 is chosen to simulate the grinding process. Second, a grinding tool is imported from the solid model of the grinding wheel. Third, the work-piece of grinding simulation of the micro drill flute is developed as shown in Figure 13. Flank surfaces at its tip are developed based on the grinding parameters $\left(\beta_{1}^{\prime}=-3^{0}, \beta_{2}^{\prime}=-45^{0}\right)$. Finally, the NC code is created to control the relative motions between the work-piece and the grinding tool. From Eq. 11 which illustrates the translation and rotation motions of the work-piece during grinding the new micro drill flute, the orbit of each point on it can be obtained. For instance, Fig. 14 shows that orbit of the point that has distance from the drill center line of $0.15 \mathrm{~mm}$. It is a helix with radius of $0.15 \mathrm{~mm}$ and pitch of $0.2598 \mathrm{~mm}$. Equation 16 indicates that grinding tool only has rotation motion and each point on it exhibits a circular orbit. The feed rate is calculated based on following parameters, i.e., $a_{x}=10 \mathrm{~mm}, a_{y}=0.1 \mathrm{~mm}, a_{z}=0, \lambda=45^{\circ}, R=0.15 \mathrm{~mm}$. The model as shown in Figure 
15 is the result of the grinding process. The obtained micro drill bit has the desired micro drill flute with its cutting lips lying in the plane containing its axis and the accuracy of the grinding wheel profile is verified. The verifying process of the accuracy of the grinding wheel profile corresponding to case II is implemented similarly.

\section{Conclusions}

Grinding of the drill flute is a crucial work of generating the micro drill. In this research the design process of grinding wheel profile was exposed for the new micro drill, which has cutting lips lying in the plane containing its axis. The process is based on the reverse problem approach with the input data of the desired cross-section of the new micro drill flute, geometric parameters of work-piece, and parameters of machine setting. Finally, two numerical examples were presented and the accuracy of grinding profile was validated by Vericut software. 


\section{References}

Chen, X., \& Rowe, W. B. (1996). Analysis and simulation of the grinding process. Part I: Generation of the grinding wheel surface. International Journal of Machine Tools and Manufacture, 36(8), 871-882. doi: http://dx.doi.org/10.1016/08906955(96)00116-2

Chyan, H. C., \& Ehmann, K. F. (1998). Development of curved helical micro-drill point technology for micro-hole drilling. Mechatronics, 8(4), 337-358. doi: http://dx.doi.org/10.1016/S0957-4158(97)00055-X

Ehmann, K. F., \& DeVries, M. F. (1990). Grinding Wheel Profile Definition for the Manufacture of Drill Flutes. CIRP Annals - Manufacturing Technology, 39(1), 153-156. doi: http://dx.doi.org/10.1016/S0007-8506(07)61024-5

Huang, C., Tarng, Y., Chiu, C., \& Huang, A. (2009). Investigation of machine vision assisted automatic resharpening process of micro-drills. Journal of Materials Processing Technology, 209(18), 5944-5954.

Huang, X., Chen, Z. S., Wang, C. Y., Zheng, L. J., \& Song, Y. X. (2016). Measurement of Micro-Drill Breakage during PCB Drilling. Paper presented at the Materials Science Forum.

Kang, S. K., Ehmann, K. F., \& Lin, C. (1996). A CAD approach to helical groove machining-I. mathematical model and model solution. International Journal of Machine Tools and Manufacture, 36(1), 141-153. doi: http://dx.doi.org/10.1016/0890-6955(95)92631-8

Kang, S. K., Ehmann, K. F., \& Lin, C. (1997). A CAD approach to helical groove machining. Part 2: Numerical evaluation and sensitivity analysis. International Journal of Machine Tools and Manufacture, 37(1), 101-117. doi: http://dx.doi.org/10.1016/0890-6955(95)00039-9

Karpuschewski, B., Jandecka, K., \& Mourek, D. (2011). Automatic search for wheel position in flute grinding of cutting tools. CIRP Annals - Manufacturing Technology, 60(1), 347-350. doi: http://dx.doi.org/10.1016/j.cirp.2011.03.113 
Lee, A.-C., \& Hoang, T.-D. (2016). Coupled lateral and torsional vibrations of the micro-drilling spindle systems. The International Journal of Advanced Manufacturing Technology, 1-17. doi: 10.1007/s00170-016-8463-1

Lee, A.-C., \& Nguyen, D.-T. (2016). Dynamic analysis of a micro drilling system by the modified transfer matrix method. MATEC Web of Conferences.

Lee, A.-C., Nguyen, D.-T., \& Wu, G.-T. (2014). Analyses of a new four-facet drill. The International Journal of Advanced Manufacturing Technology, 75(1), 411-424. doi: 10.1007/s00170-014-6105-z

Lee, A. C., Horng, J. H., Tuyen, N. D., \& Hsiao, K. M. (2013). Design of a New Micro Single Flute Drill. Paper presented at the Advanced Materials Research.

Sheth, D. S., \& Malkin, S. (1990). CAD/CAM for Geometry and Process Analysis of Helical Groove Machining. CIRP Annals - Manufacturing Technology, 39(1), 129-132. doi: http://dx.doi.org/10.1016/S0007-8506(07)61018-X

Xie, J., Zheng, J. H., Zhou, R. M., \& Lin, B. (2011). Dispersed grinding wheel profiles for accurate freeform surfaces. International Journal of Machine Tools and Manufacture, 51(6), 536-542. doi: http://dx.doi.org/10.1016/j.ijmachtools.2011.03.002

Zhang, S., Liang, Z., Wang, X., Zhou, T., Jiao, L., Yan, P., \& Jian, H. (2016). Grinding process of helical micro-drill using a six-axis CNC grinding machine and its fundamental drilling performance. The International Journal of Advanced Manufacturing Technology, 1-13. doi: 10.1007/s00170-016-8359-0

Zhang, W., Wang, X., He, F., \& Xiong, D. (2006). A practical method of modelling and simulation for drill fluting. International Journal of Machine Tools and Manufacture, 46(6), 667-672.

Zhaojun, Y., Wei, L., Yanhong, C., \& Lijiang, W. (1998). Study for increasing microdrill reliability by vibrating drilling. Reliability Engineering \& System Safety, 61(3), 229-233. doi: http://dx.doi.org/10.1016/S0951-8320(98)00004-0 


\section{Nomenclature}

\begin{tabular}{|c|c|c|c|}
\hline $\mathrm{a}_{x}, \mathrm{a}_{y}, \mathrm{a}_{z}$ & $\begin{array}{l}\text { coordinates of the tool } \\
\text { frame origin }\end{array}$ & $\lambda$ & rotational angle of the tool frame \\
\hline$h_{0}$ & helix angle & $\rho$ & semi point angle \\
\hline$n$ & common normal & $\phi_{1}^{\prime}$ & primary semi-point angle \\
\hline$L$ & helix pitch & $\psi$ & chisel angle \\
\hline$R$ & drill radius & & \\
\hline$R_{1}$ & arc radius & & Subscript \\
\hline$u, v$ & curvilinear parameters & M & coordinates in machine frame \\
\hline $\boldsymbol{r}, \boldsymbol{r}_{D}, \boldsymbol{r}_{\mathrm{W}}$ & location vectors & $\mathrm{T}$ & coordinates in tool frame \\
\hline$\beta_{1}^{\prime}$, and $\beta_{2}^{\prime}$ & tilt angles & $\mathrm{W}$ & coordinates in work-piece frame \\
\hline
\end{tabular}


Table 1. Simulation parameters

\begin{tabular}{|c|c|c|}
\hline Parameters & Case I & Case II \\
\hline$a_{x}$ & $10 \mathrm{~mm}$ & $11 \mathrm{~mm}$ \\
\hline$a_{y}$ & $0.1 \mathrm{~mm}$ & $0.1 \mathrm{~mm}$ \\
\hline$a_{z}$ & $0 \mathrm{~mm}$ & $0 \mathrm{~mm}$ \\
\hline$\lambda$ & $45^{0}$ & $65^{0}$ \\
\hline$\gamma$ & $20^{\circ}$ & $25^{0}$ \\
\hline$\phi_{1}^{\prime}$ & $65^{0}$ & $65^{0}$ \\
\hline$R$ & $0.15 \mathrm{~mm}$ & $0.2 \mathrm{~mm}$ \\
\hline$R_{1}$ & $0.09707 \mathrm{~mm}$ & $0.13514 \mathrm{~mm}$ \\
\hline$x_{01}$ & $0.11038502 \mathrm{~mm}$ & $0.13635298 \mathrm{~mm}$ \\
\hline$y_{01}$ & $-0.025228061 \mathrm{~mm}$ & $-0.05121236 \mathrm{~mm}$ \\
\hline$\beta_{1}^{\prime}$ & $-3^{0}$ & $-2^{0}$ \\
\hline$\beta_{2}^{\prime}$ & $-45^{0}$ & $-45^{0}$ \\
\hline Interval of $u$ in Eqs. 1 and 2 & $4.7^{0} \leq u \leq 11.14^{0}$ & $3.52^{0} \leq u \leq 11.14^{0}$ \\
\hline$\alpha_{1}, \alpha_{2}$ in Eqs.5 and 6 & $\alpha_{1}=84^{0}, \alpha_{2}=46.77^{0}$ & $\alpha_{1}=77.12^{0}, \alpha_{2}=46.24^{0}$. \\
\hline
\end{tabular}




\section{List of Figures}

Figure 1. New micro drill bit

Figure 2. The grinding process of the new micro drill bit; (a) Step 1, (b) Step 2, (c) Step 3, (d) Step 4, (e) Step 5

Figure 3. Cross-section of the new micro drill flute

Figure 4. Grinding of flank surfaces; (a) Primary flank surface, (b)Secondary flank surface

Figure 5. Grinding of a new micro drill flute

Figure 6. Grinding wheel and work-piece tangency for the inverse problem

Figure 7. Desired cross-section of the new micro drill flute in case I

Figure 8. Grinding wheel profile for the new micro drill flute in case I

Figure 9. Desired cross-section of the new micro drill flute in case II

Figure 10. Grinding wheel profile for the new micro drill flute in case II 
Figure 11. The grinding wheel for the drill flute; (a) Developed grinding wheel in Solidworks software, (b) The grinding wheel

Figure 12. The 9-axis CNC grinding machine

Figure 13. Micro drill work-piece

Figure 14. Point orbit of work-piece during machining the micro drill flute

Figure 15. The ground micro drill flute 


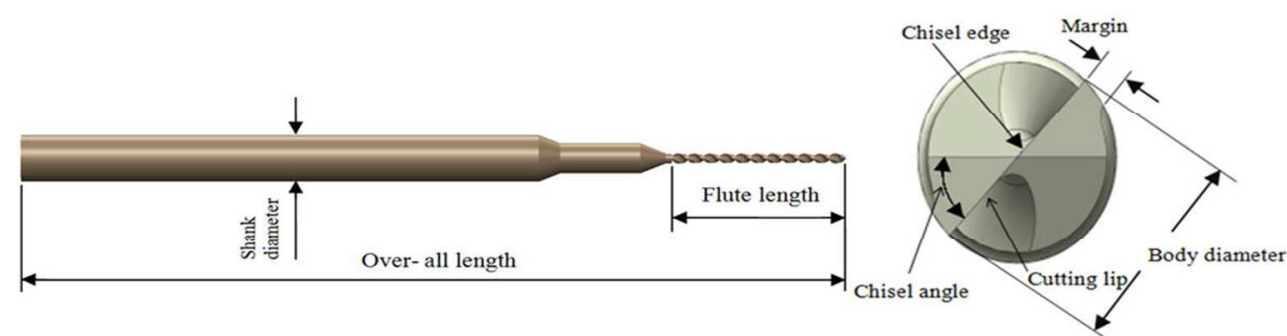

$328 \times 95 \mathrm{~mm}(96 \times 96 \mathrm{DPI})$ 


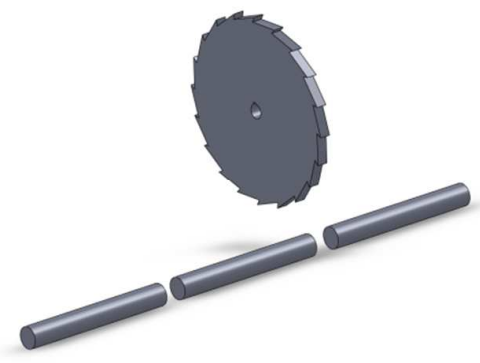

(a) Step 1

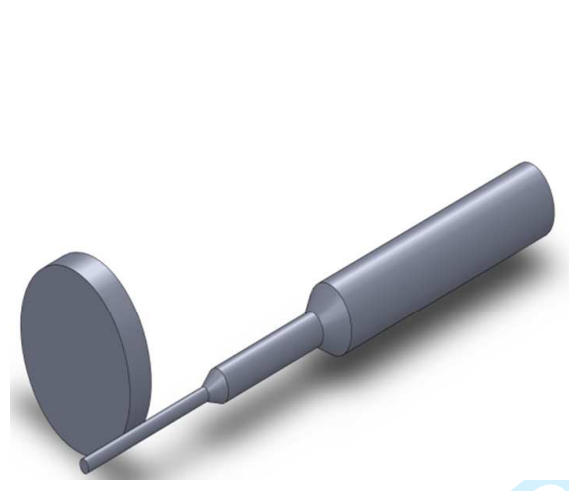

(b) Step 3

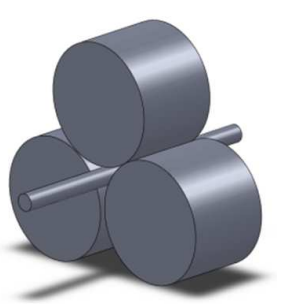

(b) Step 2

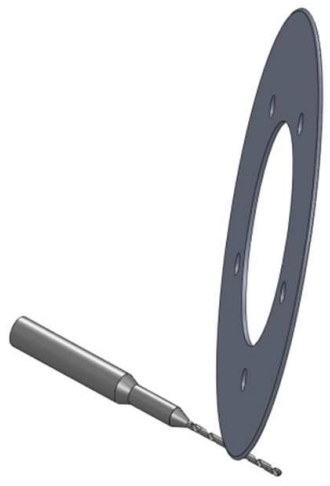

(d) Step 4

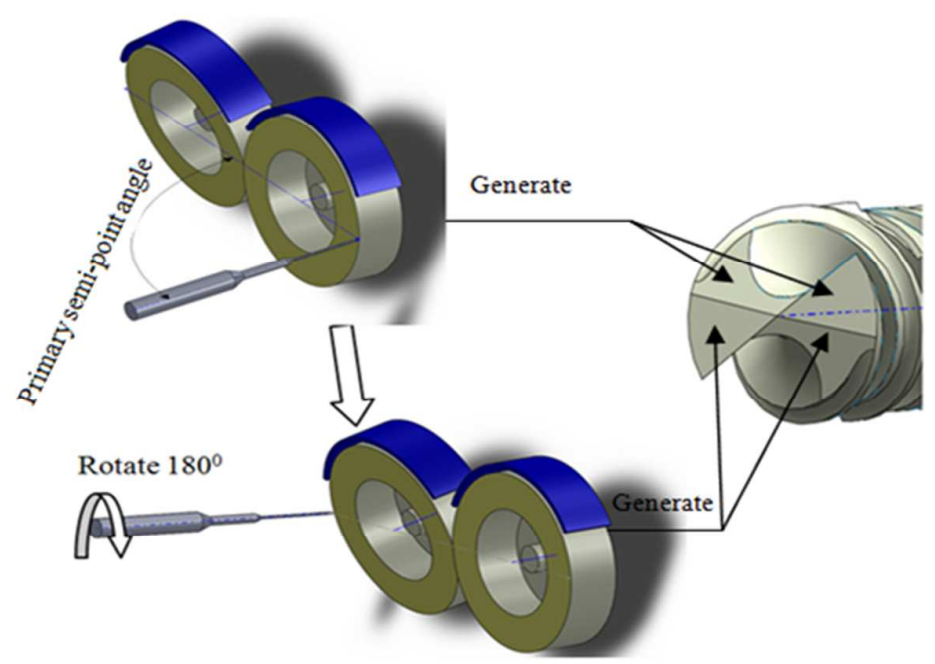

(e) Step 5 


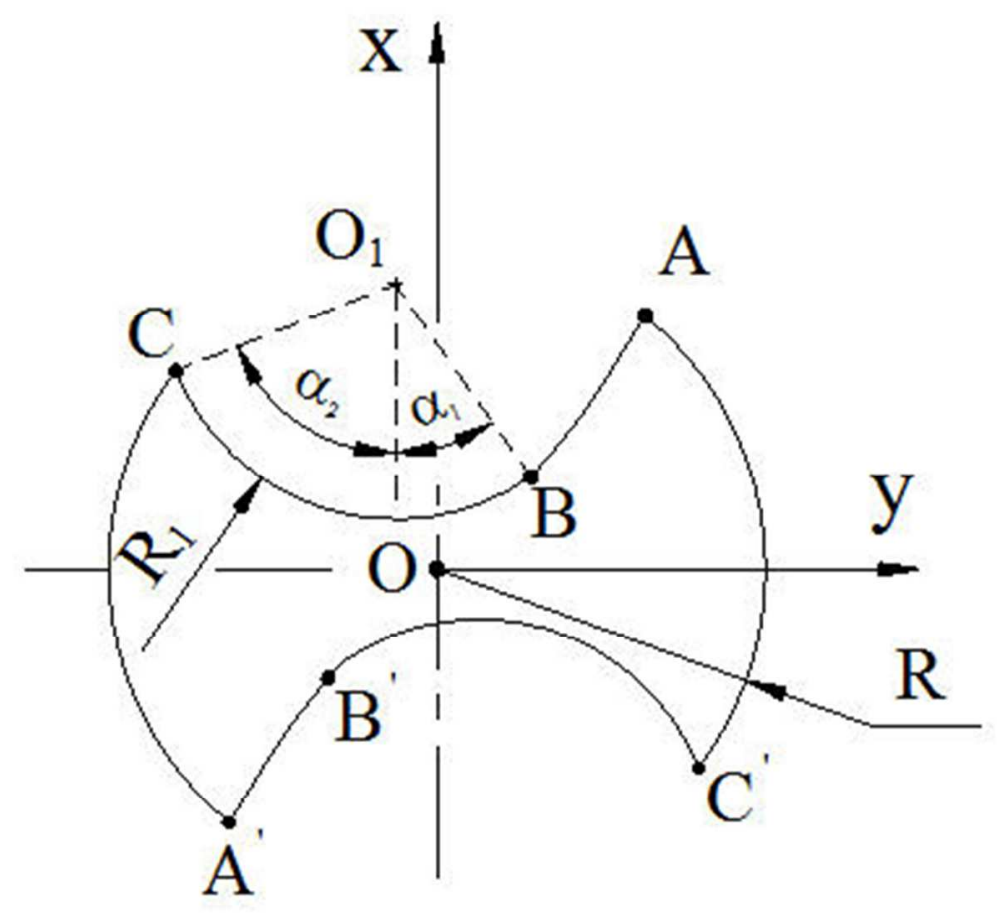

$110 \times 97 \mathrm{~mm}(96 \times 96 \mathrm{DPI})$ 


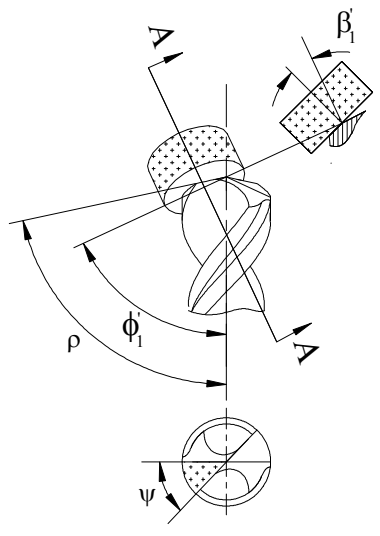

(a): Primary flank surface

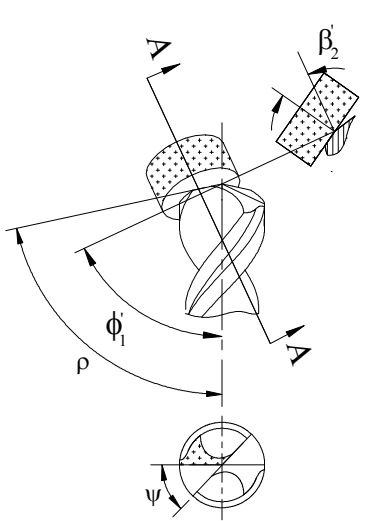

(b): Secondary flank surface 


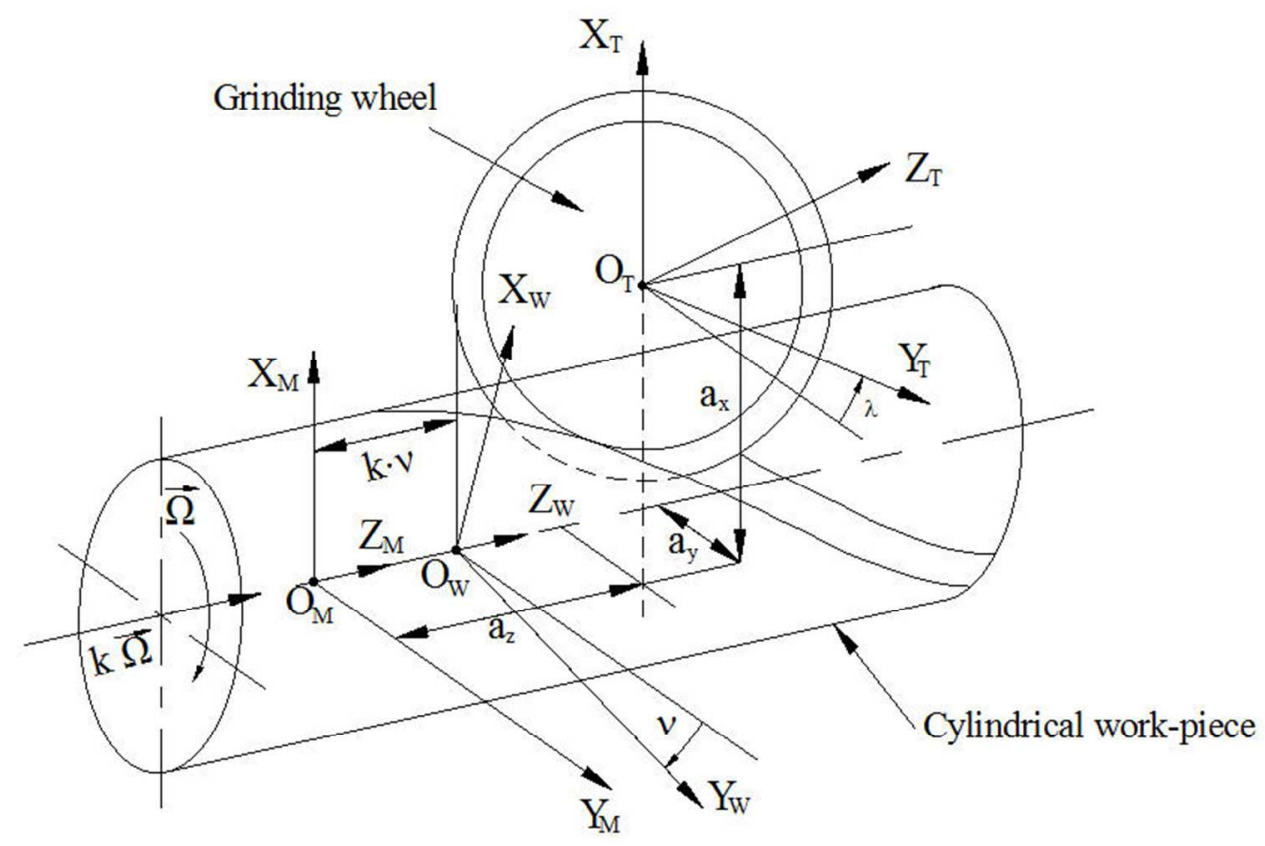

$229 \times 153 \mathrm{~mm}(96 \times 96 \mathrm{DPI})$ 


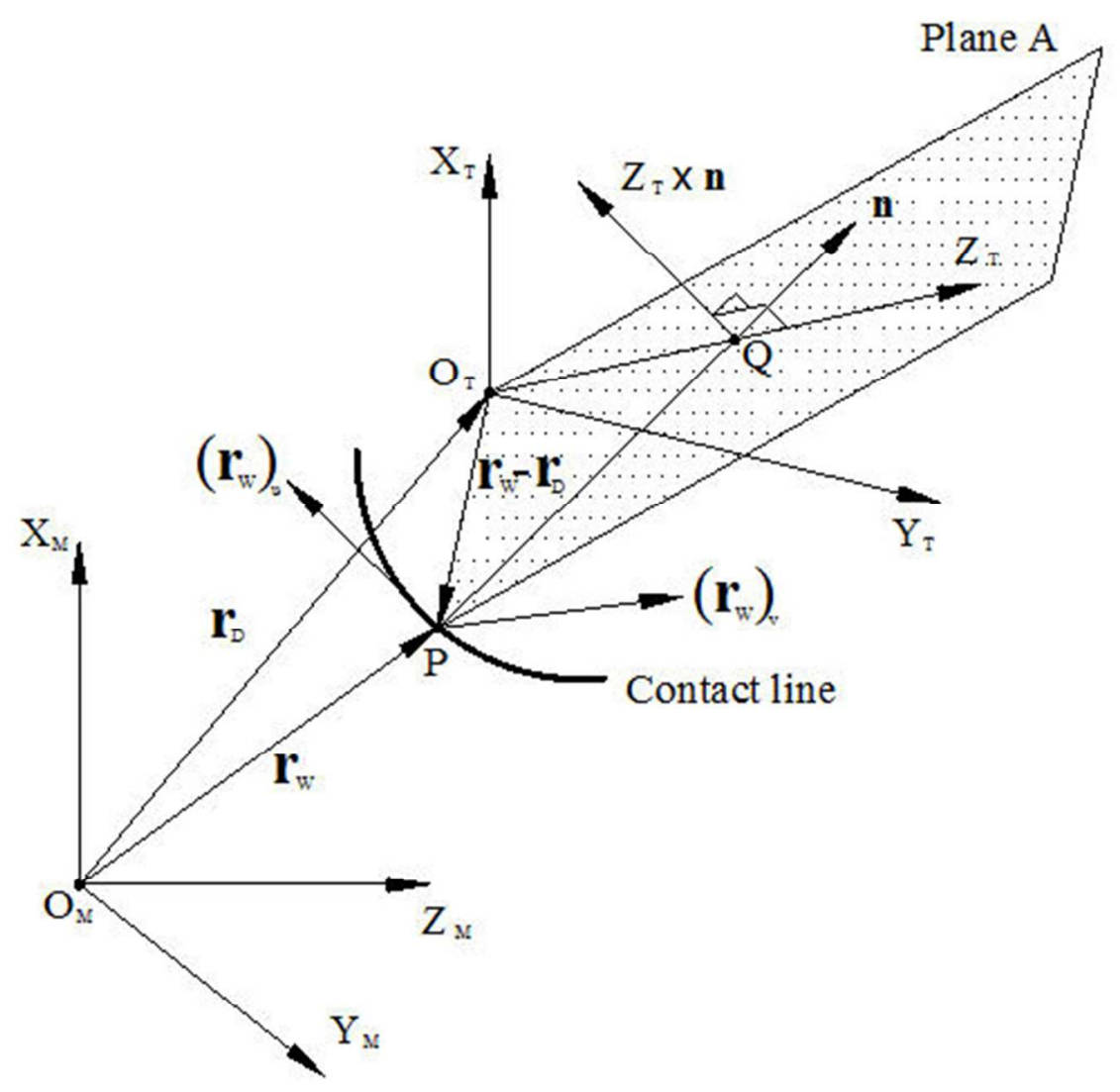

$152 \times 147 \mathrm{~mm}(96 \times 96 \mathrm{DPI})$ 


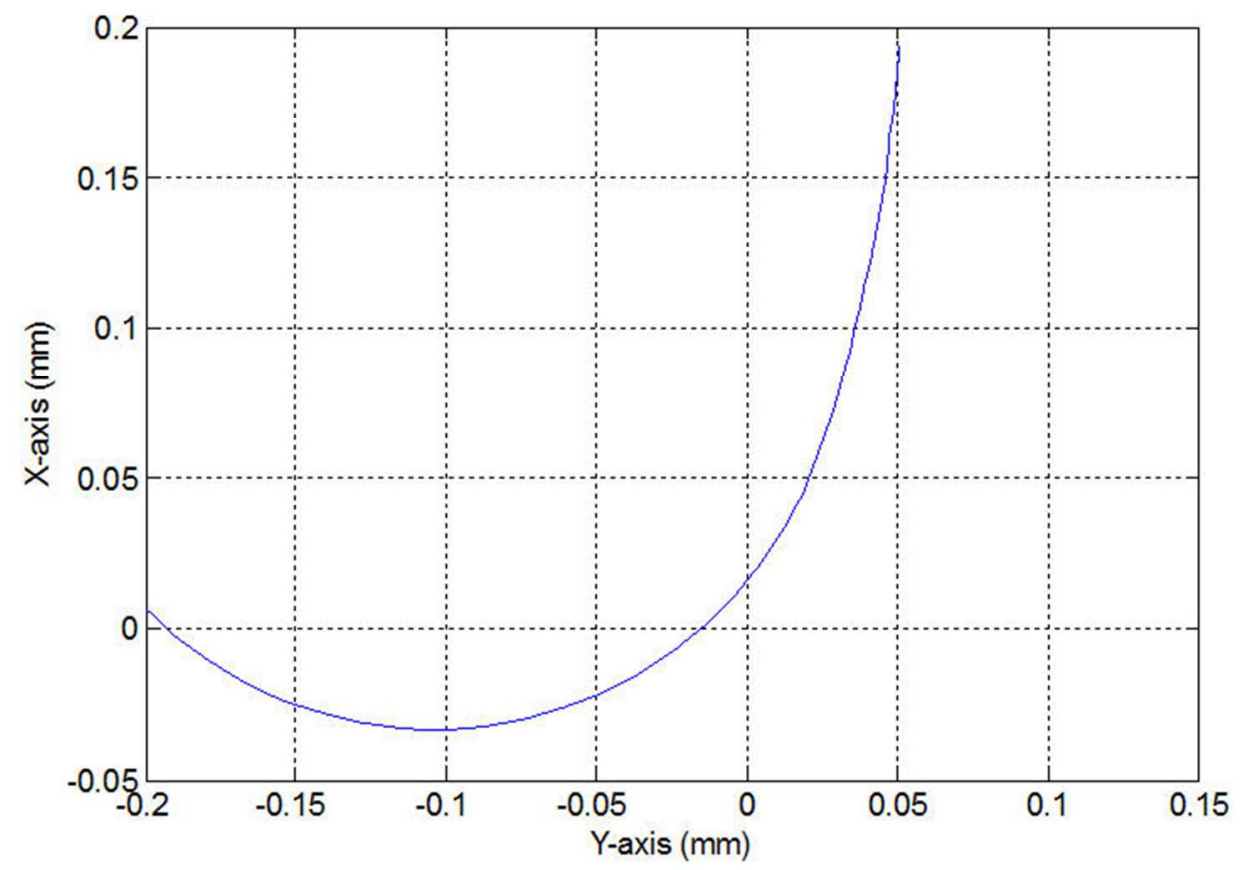

$204 \times 142 \mathrm{~mm}(96 \times 96$ DPI $)$ 


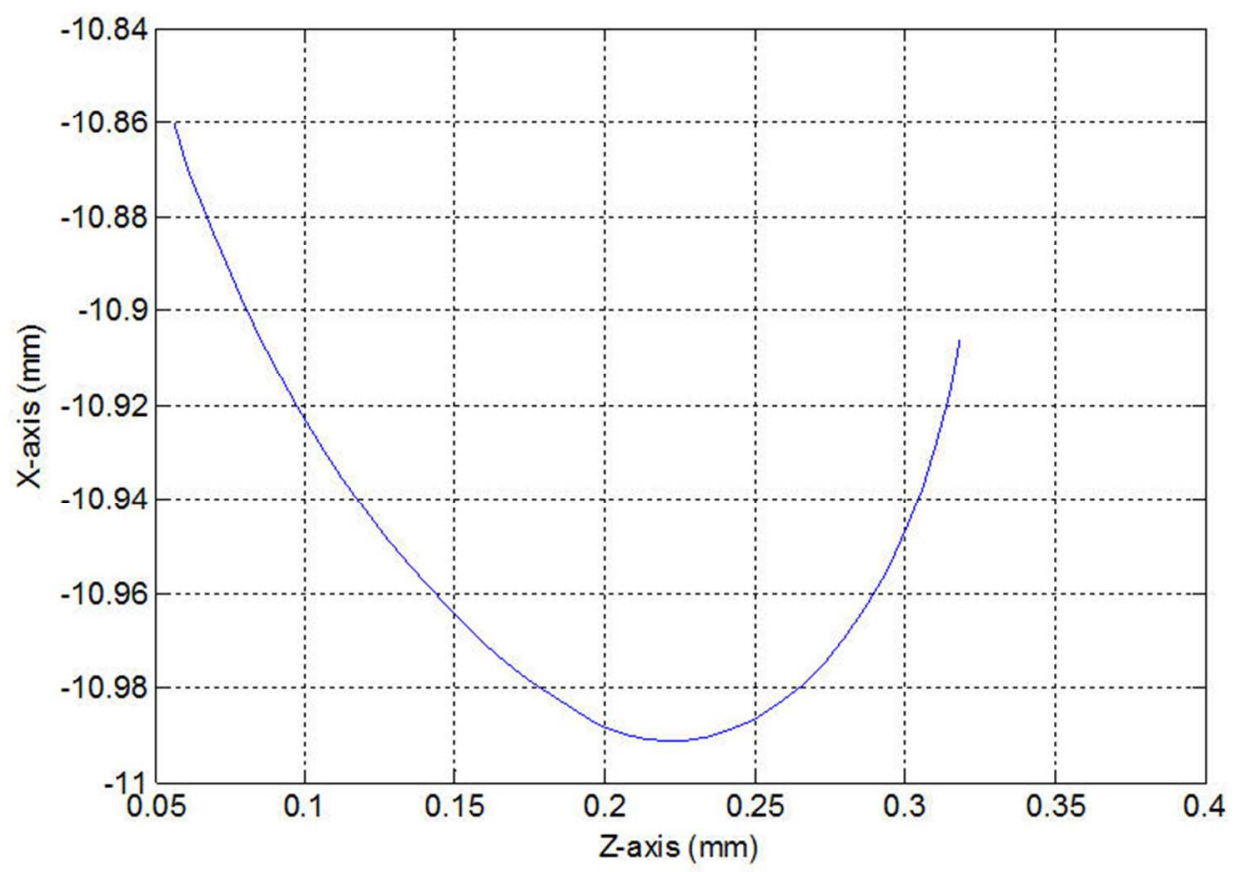

$214 \times 148 m m(96 \times 96$ DPI) 


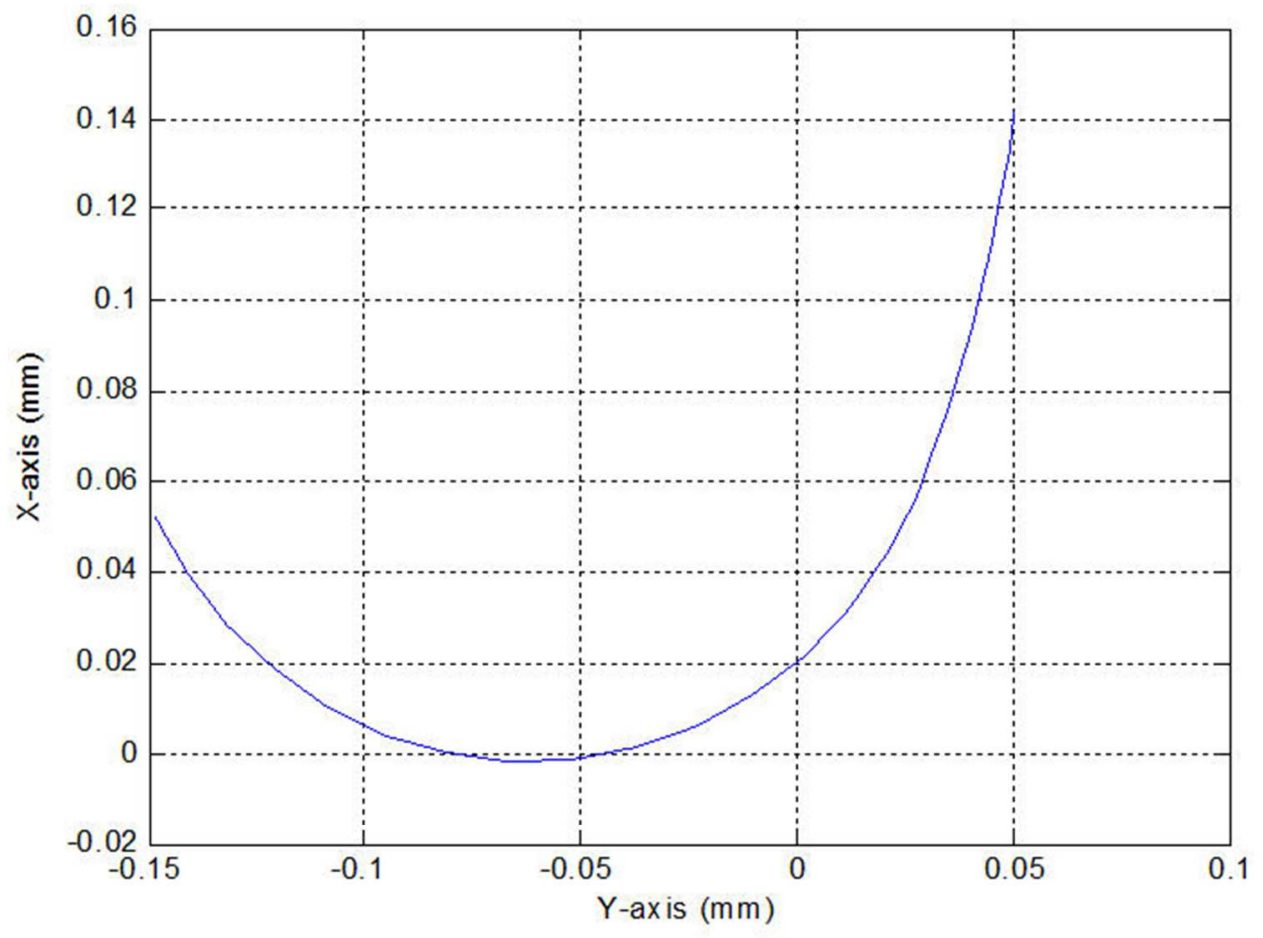

$192 \times 143 \mathrm{~mm}(96 \times 96 \mathrm{DPI})$ 


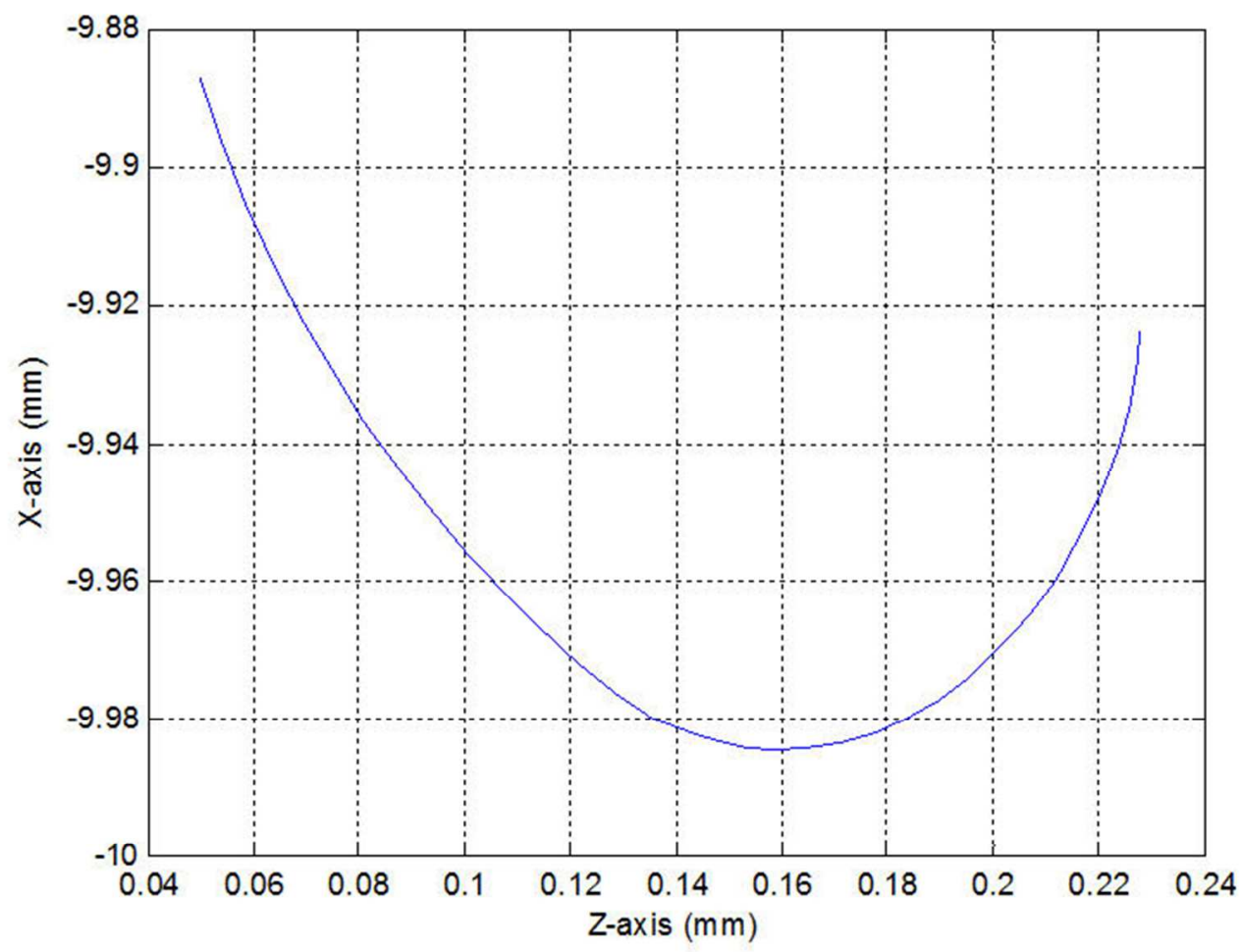

$196 \times 152 \mathrm{~mm}(96 \times 96 \mathrm{DPI})$ 

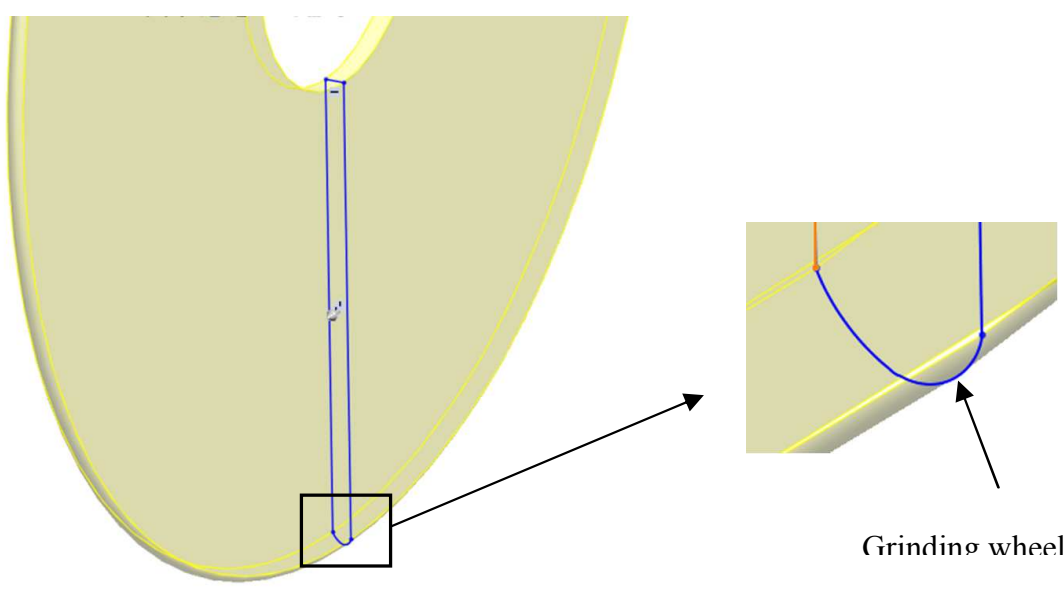

Grindino wheel nrofile

(a) : Developed grinding wheel in Solidworks software

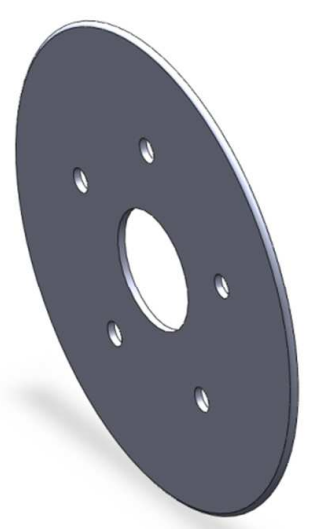

(b): The grinding wheel 


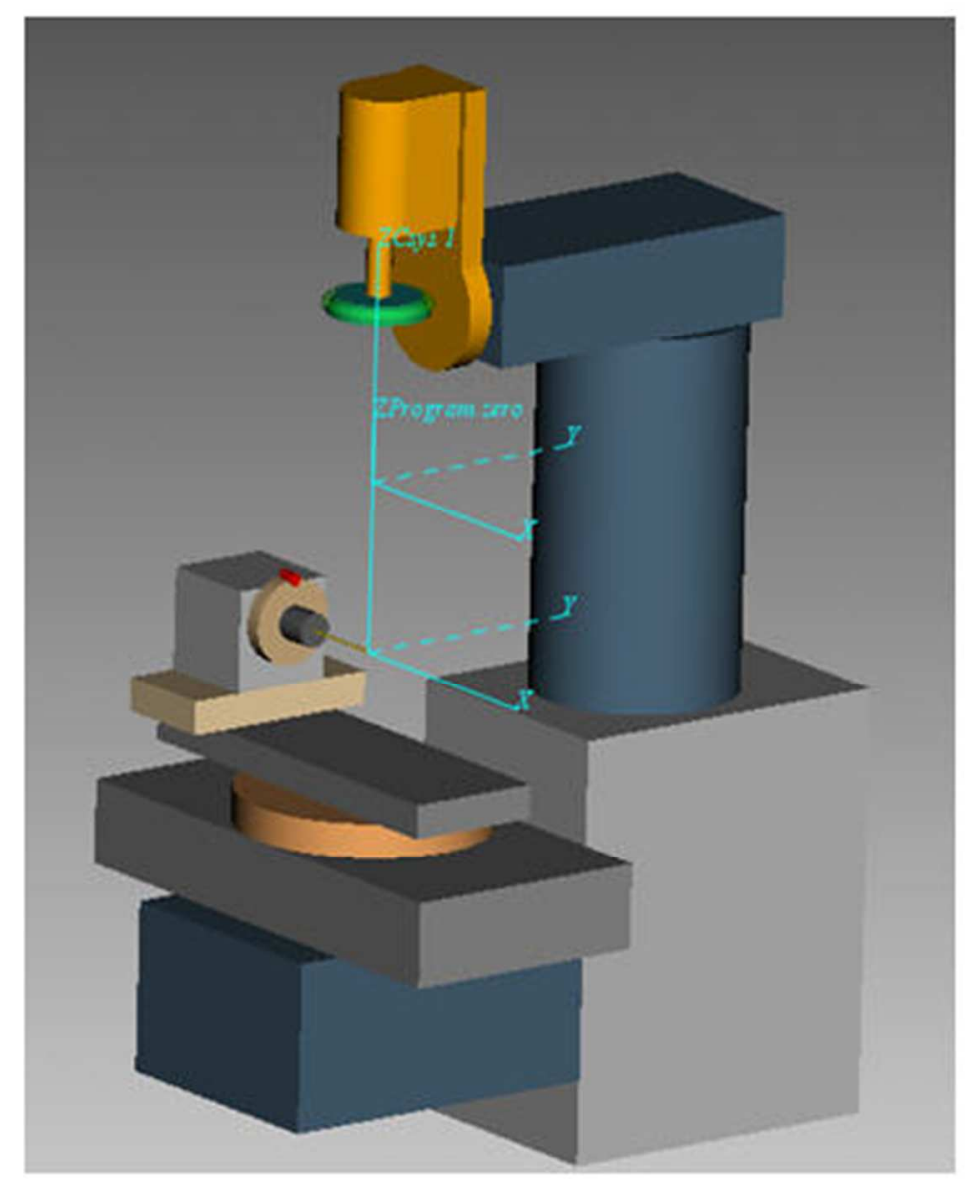

$104 \times 123 \mathrm{~mm}(96 \times 96 \mathrm{DPI})$ 


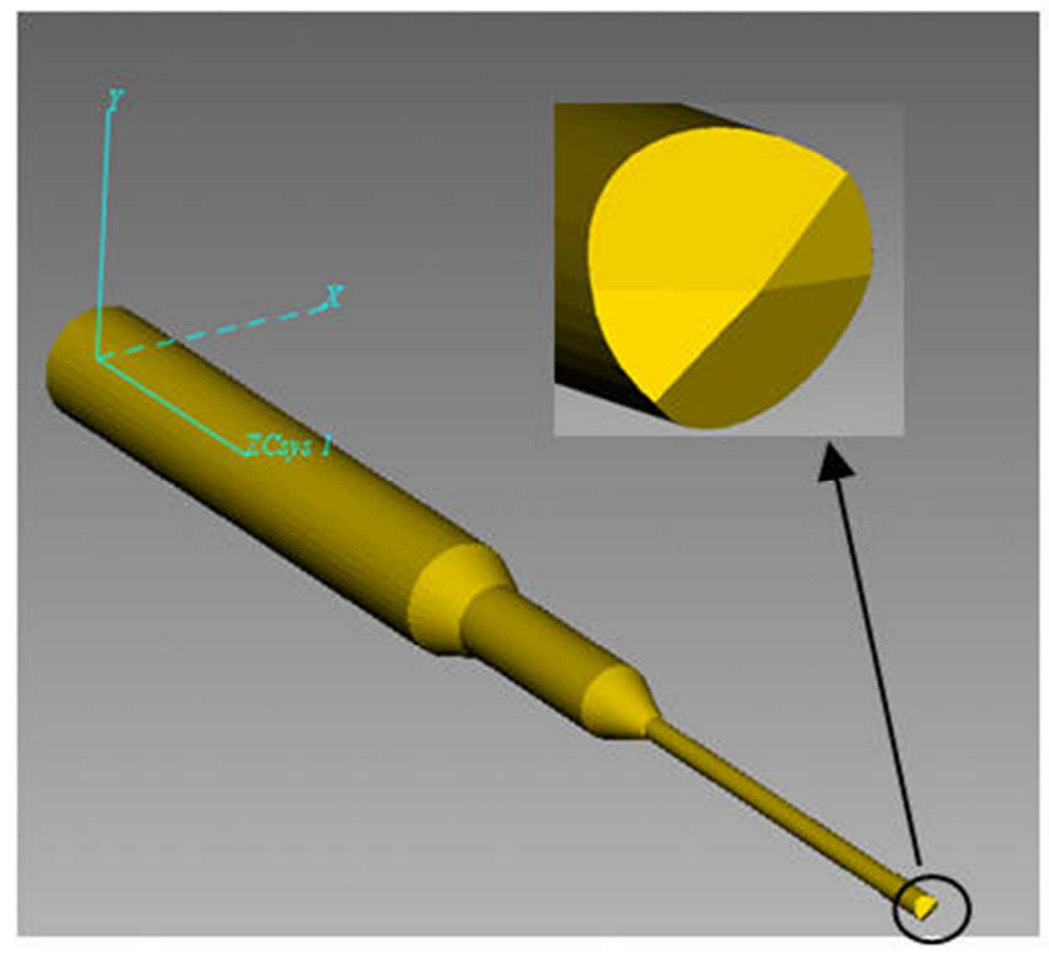

$110 \times 100 \mathrm{~mm}(96 \times 96 \mathrm{DPI})$ 


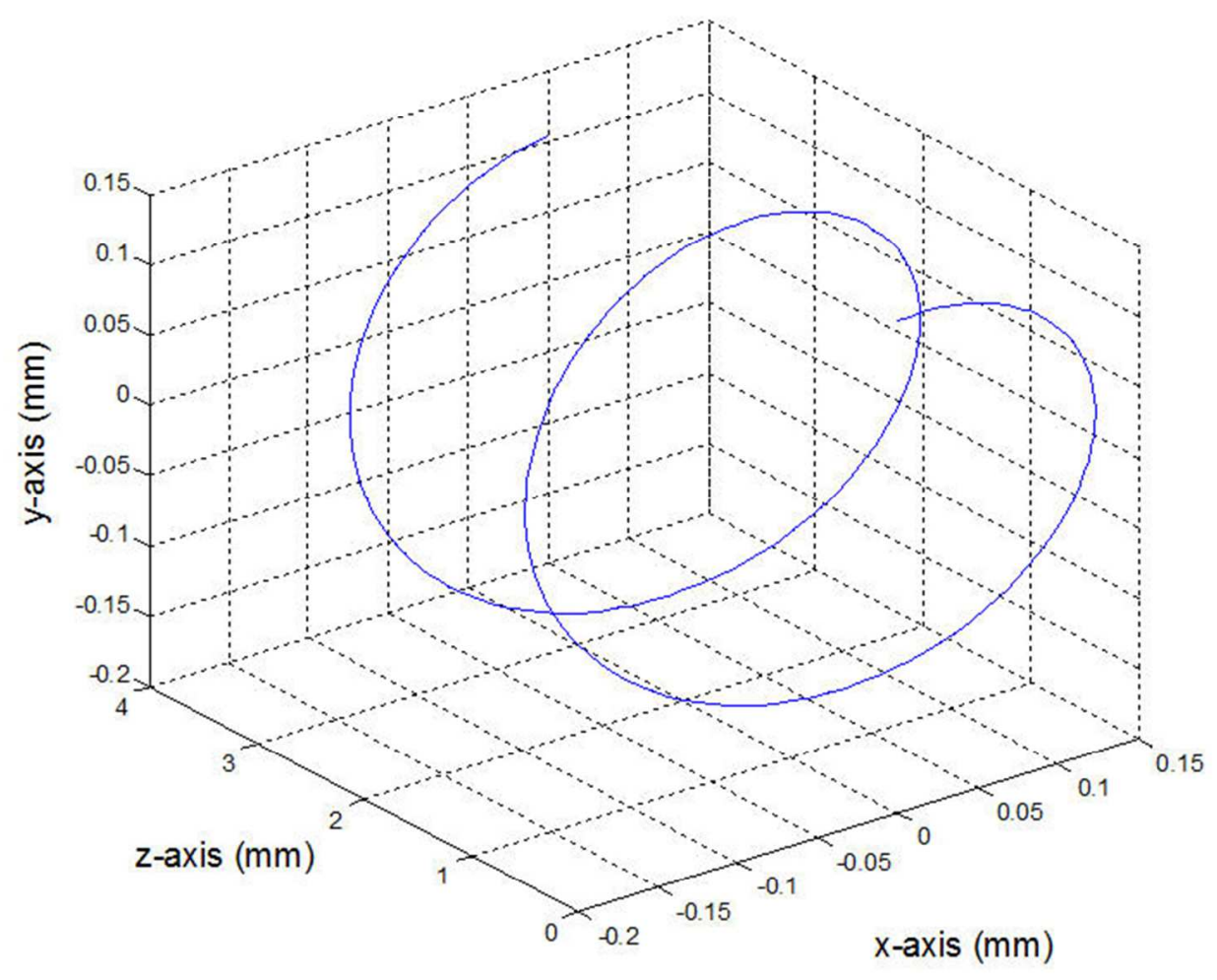

$196 \times 155 \mathrm{~mm}(96 \times 96 \mathrm{DPI})$ 


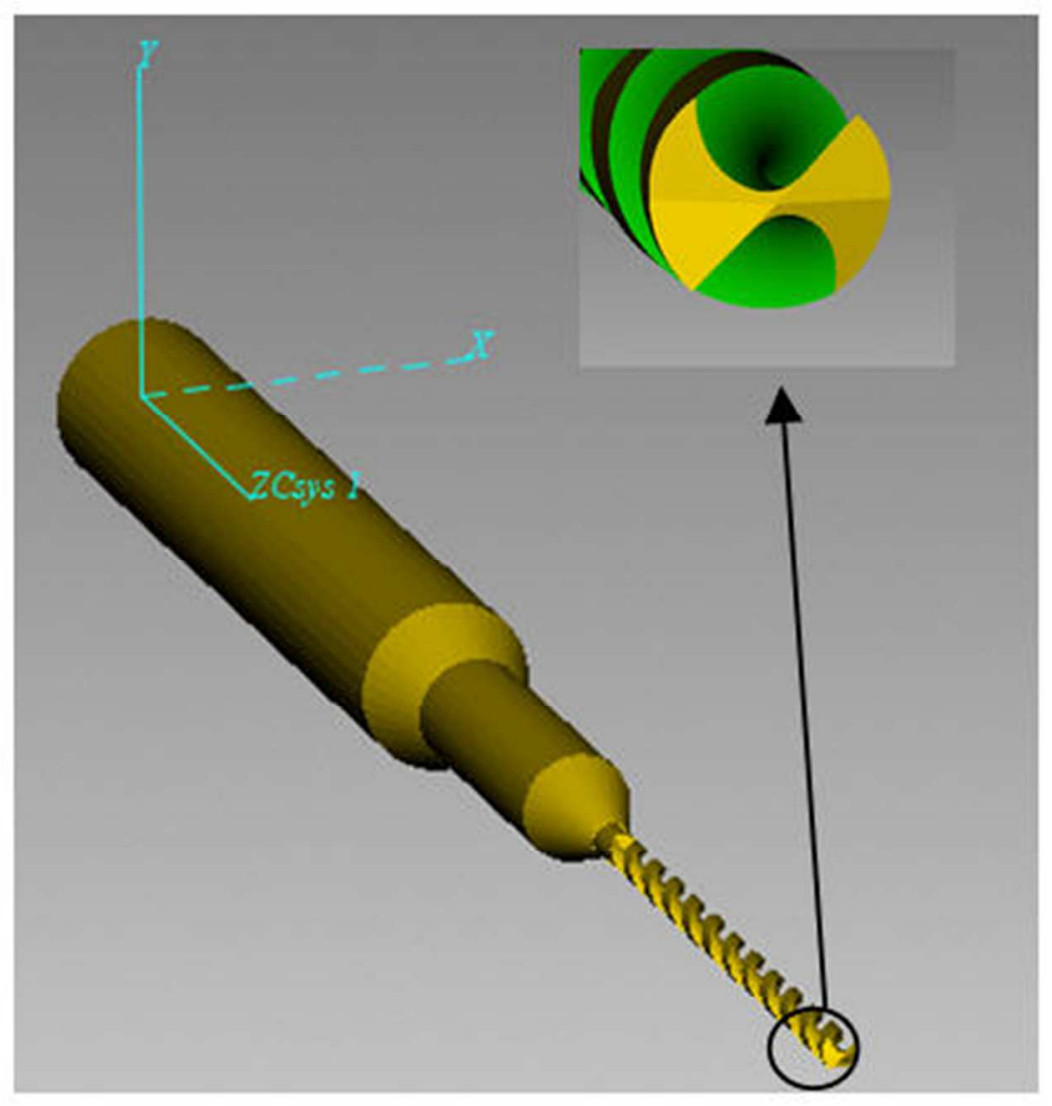

$115 \times 118 \mathrm{~mm}(96 \times 96 \mathrm{DPI})$ 


\section{Appendix}

( $\mathrm{G}$ codes for $\mathrm{NC}$ grinding micro tool flute)

O9999

G21G54G0G90G80G40G00 X0 Y0 Z0 A0 B0 C0 U25 V0 W0

T1M6M3S2000 \rotate grinding wheel by 2000 round per minute (RPM)

C45V0.1 W10 \set up the grinding wheel coordinate

G1U-4.89726A-1080 Igrind the first flute

G00A-180 B0 C0 U25 V0 W45

C45V0.1 W10

G1U-4.89726A-1080 \grind the first flute

G0 X0 Y0 Z15. A0 B0 C0 U0 V0 W10.0

M05

M02 